\title{
CFD analysis of three and four blades movable vanes type vertical axis wind turbine having movable vanes
}

\author{
Kadhim H. Suffer ${ }^{\mathrm{a}}$, Ghulam A. Quadir ${ }^{\mathrm{b}}$, Khairul A. Ismail ${ }^{\mathrm{a}}$, Ryspek U. ${ }^{\mathrm{a}}$ \\ ${ }^{a}$ School of Manufacturing Engineering, University Malaysia Perlis, Arau (02600), Perlis, Malaysia \\ ${ }^{b}$ School of Mechatronic Engineering, University Malaysia Perlis, Arau (02600), Perlis, Malaysia
}

\begin{abstract}
A thorough understanding of the principles of aerodynamics and structural dynamics of the rotor system is required for designing a wind turbine system that can generate power with high efficiency. The power generated by a Vertical Axis Wind Turbine (VAWT) depends on the drag force generated by the individual blades and interactions between them in a rotating configuration. The present analysis is an attempt to predict numerically the coefficient of drag and other aerodynamic parameters for a three and four blades Vane type Vertical Axis Wind Turbine (VVAWT) with different blades and vanes position. Commercial Computational Fluid Dynamics CFD softwares GAMBIT and FLUENT are used in the numerical analysis where the Shear Stress Transport (SST) k- $\omega$ turbulence closure model is used. The results are found to be similar in nature to those reported for VAWT having different blade designs.
\end{abstract}

Keywords: Wind energy, vertical axis wind turbine, computational fluid dynamics, performance analysis, $k-\omega$ turbulence model

\section{Introduction}

In the 21th century, the energy demand is very high. Wind power is one of the alternative energies because of cleanliness and emissions-free power generation technology. Also it is available by capturing the energy from nature and has none of the polluting effects associated with conventional fuels. Wind turbine is a machine for converting the kinetic energy available in the wind into mechanical energy. Modern wind turbines are divided into two main types based on their rotational axis: The Horizontal Axis Wind Turbine (HAWT) and the Vertical Axis Wind Turbine (VAWT). The efficiency of the VAWTs depends on the aerodynamics of the wind blades. Improvement in the aerodynamic characteristics of VAWT can be done by numerical simulation using Computational Fluid Dynamics CFD.

Many wind turbine researches are focused on accurately predicting efficiency. Being able to predict wind turbine performance numerically offers a possibility to reduce the number of experimental tests that are needed. Wanga et al. [1] reported the numerical simulation for the aerodynamic performance of VAWT at different wind velocities and unsteady flow field of the vertical axis wind turbine using Reynolds average Navier-Stokes equations and Realizable k- $\varepsilon$ model. Rolland et al. [2] developed a CFD based computational model to analyse the aerodynamic performance of their novel designed Vertical Axis Wind Turbine (VAWT), carried out experiments, and found their predicted results to be in good agreement with experiment. Aranake et al. [3] performed a computational analysis of diffuser-augmented turbines by using high resolution computations of the Reynolds Averaged Navier-Stokes equations supplemented with a transition model. The performance of a Savonius wind turbine with constant crosssections was examined by Kacprzak et al. [4] by means of quasi 2D flow predictions using ANSYS CFX. The Shear Stress Transport (SST) k- $\omega$ turbulence model was used based on earlier similar studies by Mohamed et al. [5]. This turbulence model is known to give accurate predictions of flow separation under

Manuscript received July 31, 2016; revised October 21, 2016.

Corresponding author. Tel.: +601131322007; E-mail address: kadhim_askar@yahoo.com

doi: 10.12720/sgce.5.4.259-263 
adverse pressure by an implementation of the transport effects on the formulation of the eddy viscosity.

\section{Current Simulation}

The main goal of this current research is to simulate numerically first for the three and then for the four blades vane type vertical axis wind turbine (VVAWT) with different blade shape under movable vanes conditions to investigate its aerodynamic performance. In the first simulation the turbine rotor consists of three blades of cavity shape each one having three vanes with angles $120^{\circ}$ between each blade. Similarly for the second case the turbine rotor consists of four blades with $90^{\circ}$ angle between them and each blade having three vanes. It is expected that these designs increase drag force substantially. Solidworks 2013 software is used to design turbine geometry as shown in Fig. 1 (a and b). The top section view of the computational domain with the boundary conditions for three and four blades turbines are shown in Fig. 1 (c and d). The inlet is defined as a velocity inlet and the simulation is carried out for different inlet velocities 14,20 , and $25 \mathrm{~m} / \mathrm{s}$ but the result is presented for $14 \mathrm{~m} / \mathrm{s}$ only, while the outlet is set as a pressure outlet, keeping the pressure constant. The no slip shear condition is applied on the turbine blade, which sets the relative velocity of blades to zero. For numerical investigation, CFD software GAMBIT is used for meshing the geometry and specifying the boundary conditions, whereas ANSYS FLUENT 14.5 software is used to solve the Navier-Stokes equations. The Shear Stress Transport (SST) $k$ - $\omega$ turbulence model is used in the analysis mainly because it is better than the other turbulence models available as reported earlier [6].

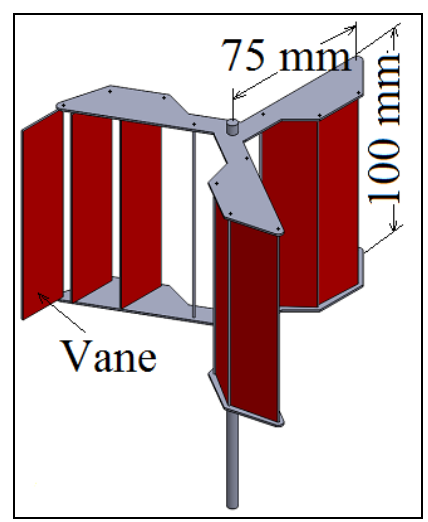

(a)

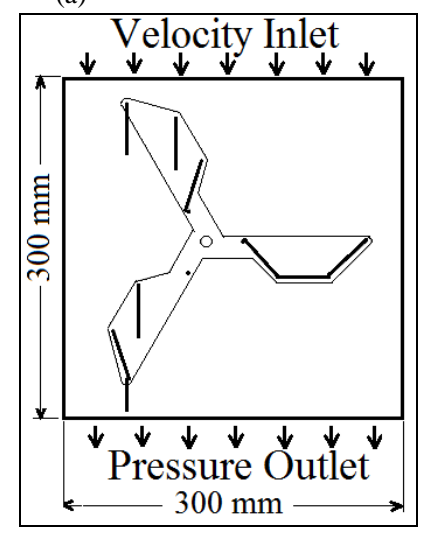

(c)

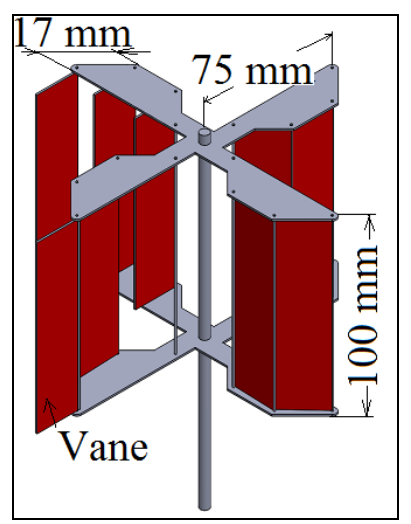

(b)

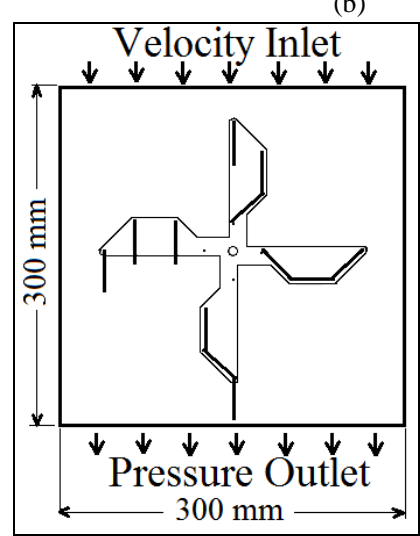

(d)

Fig. 1. (VVAWT): (a) three blades design (b) four blades design (c) three blades computational domain (d) four blades computational domain. 
The numerical simulations were carried out for fixed blade position representing its angular positions of $0^{\circ}, 30^{\circ}, 45^{\circ}, 60^{\circ}, 90^{\circ}$ and $120^{\circ}$ for three blades design and $0^{\circ}, 30^{\circ}, 45^{\circ}, 60^{\circ}, 90^{\circ}$ for four blades design.

\section{Results and Discussion}

It can be observed from Fig. 2 (a) that residual plot, which has very small spikes in turbulent kinetic energy and specific dissipation rate for the residual being set as $10^{-5}$. Fig. 2 (b) shows the variation of predicted drag coefficient $(\mathrm{Cd})$ with different blade angular positions. It is evident that $\mathrm{Cd}$ for three blades design is maximum (1.364) at zero blade angle, and minimum (1.071) at $60^{\circ}$ blade angle and again maximum at $120^{\circ}$ blade angle. For four blades design $\mathrm{Cd}$ is maximum (1.432) at zero blade angle, minimum (1.126) at $45^{\circ}$ blade angle and again maximum at $90^{\circ}$ blade angle. For three blades design at $120^{\circ}$ blade angle, actually the next blade takes the position of its first blade because the angle between the turbine blades is $120^{\circ}$, while this happens at $90^{\circ}$ for four blades design because the angle between the turbine blades is $90^{\circ}$. From Fig. 2 (b) it is can be observed that the Cd for four blades design is higher than for three blades design. Fig. 3 shows the contour of static pressure distribution in and around turbine blade at $0^{\circ}$ and $45^{\circ}$ angular positions for three and four blades turbines.
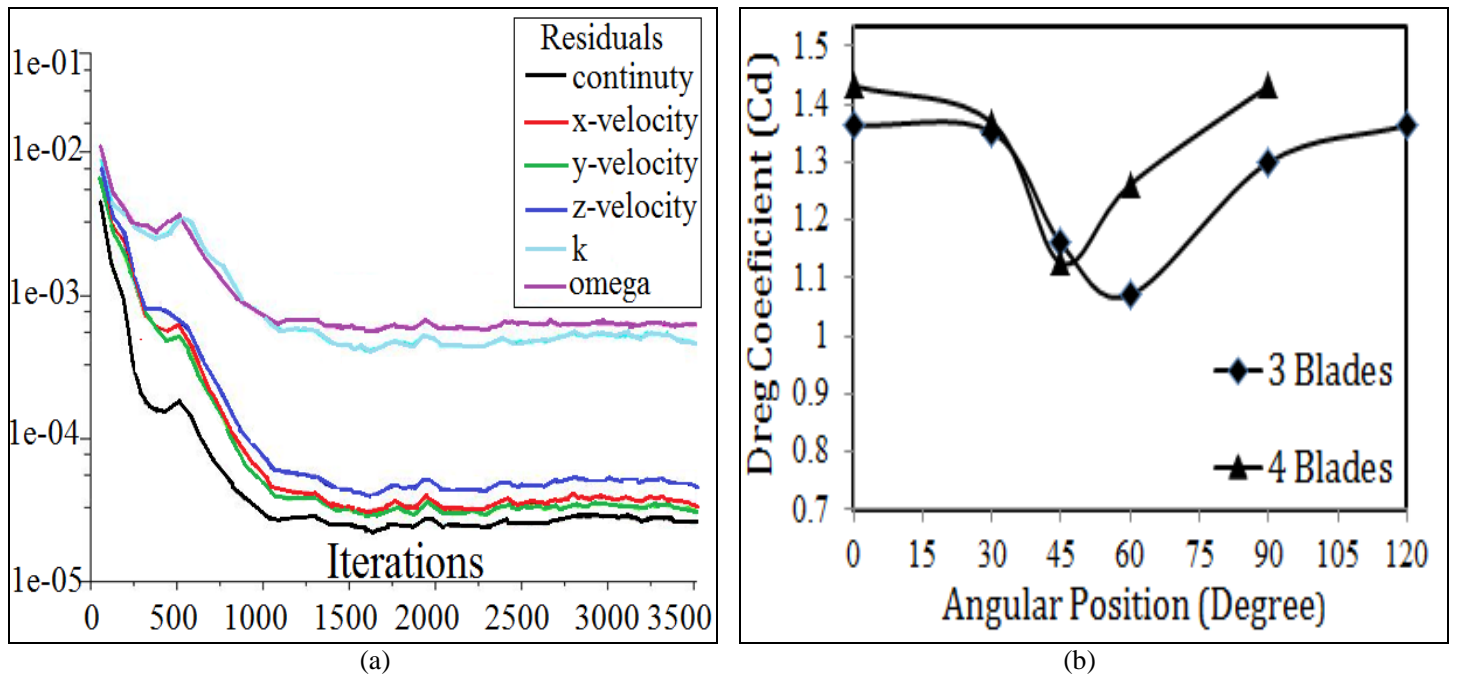

Fig. 2. (a) convergence history for continuity, momentum, and turbulence equations; (b) drag coefficient for first blade angular positions.

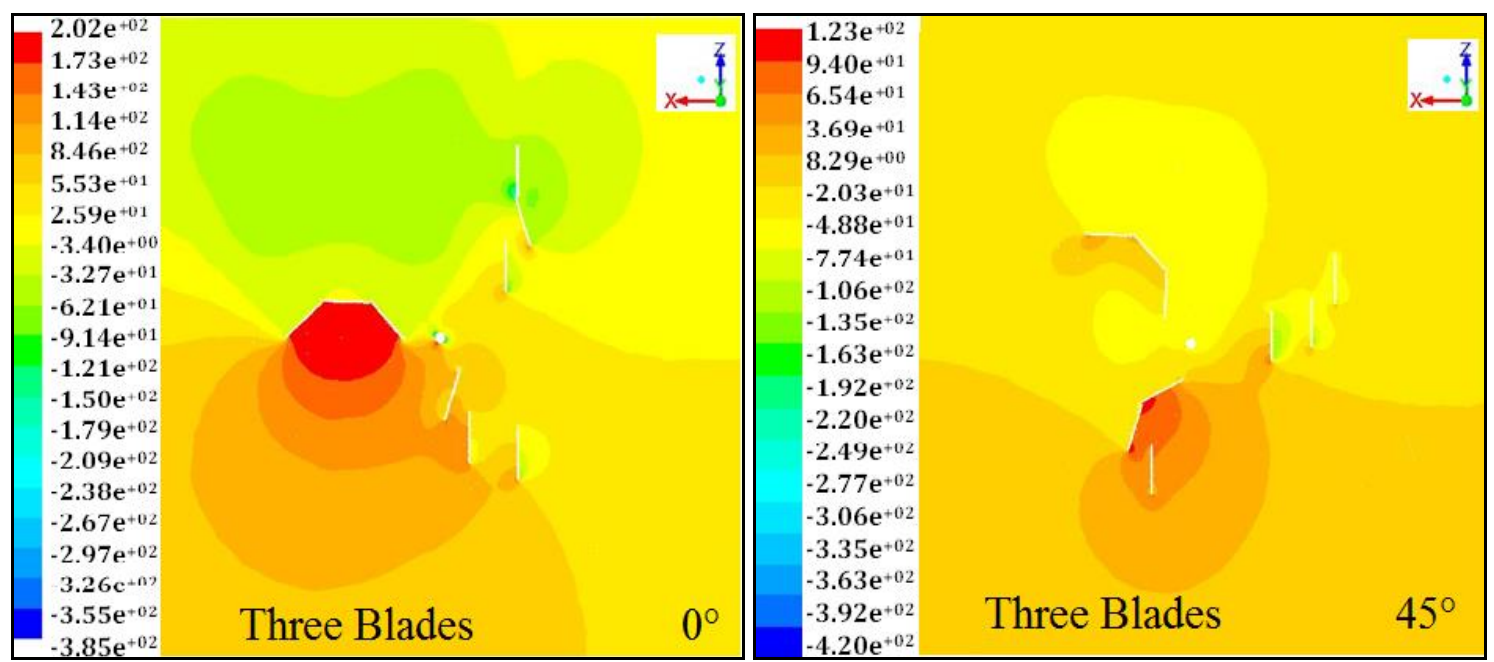




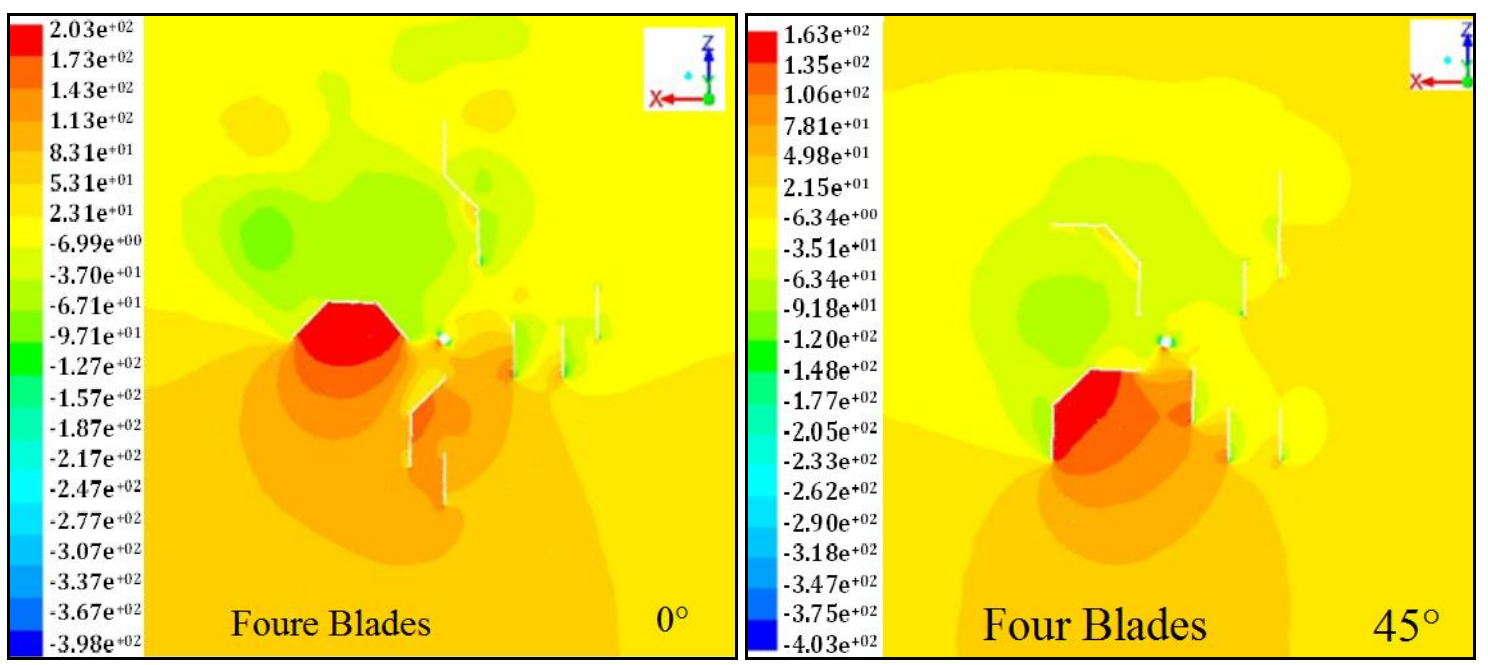

Fig. 3. Contour of static pressure distribution in and around turbine blade at different angular positions for three and four blades design.

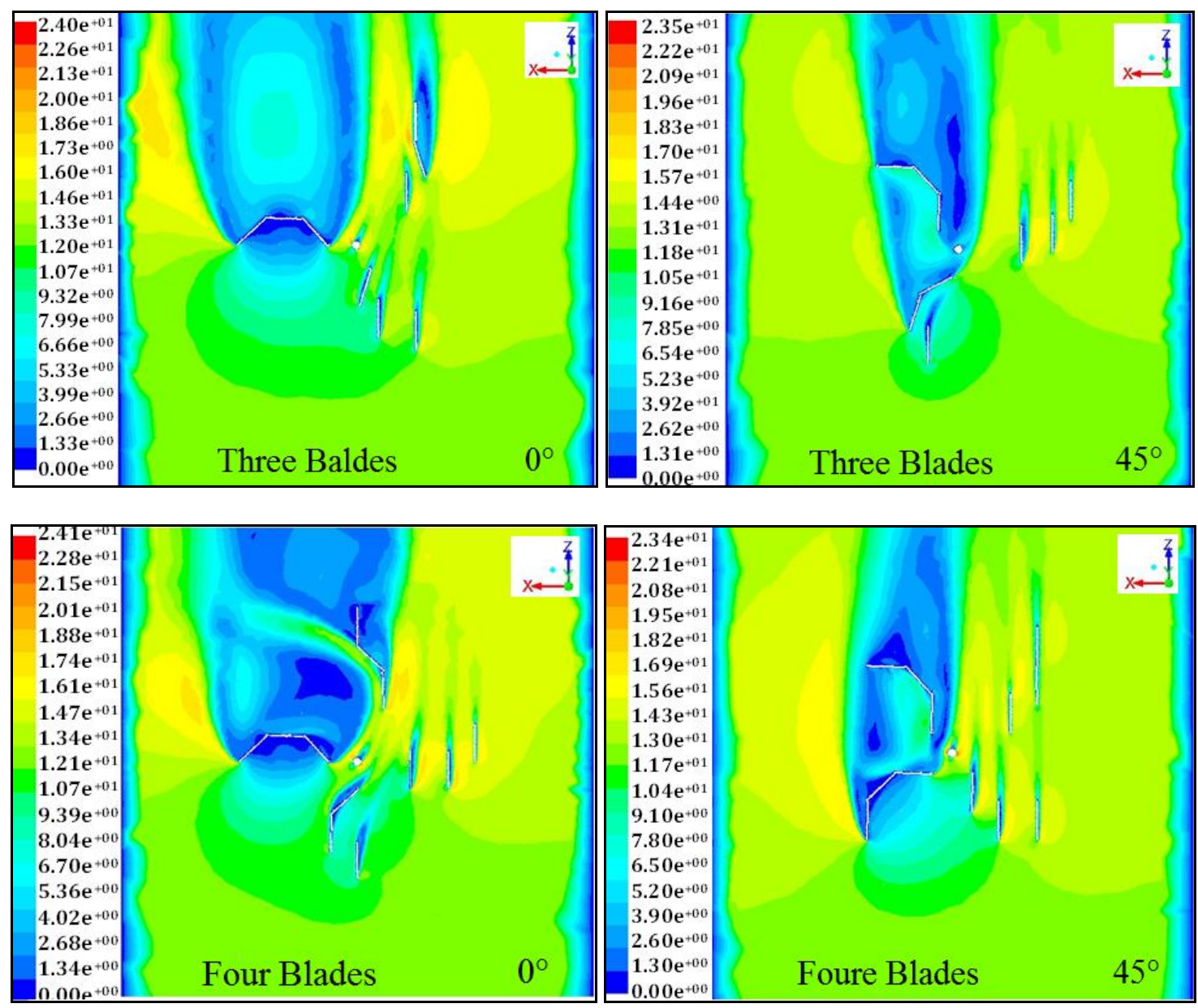

Fig. 4. Contour of velocity distribution in and around turbine blade at different angular positions for three and four blades design. 
Fig. 3 shows the pressure drop occurring across the rotor from upstream to downstream side. For three blades design the maximum static pressure drop $(1.43 \mathrm{E}+02 \mathrm{~Pa})$ is found in the case of blade angular position of $90^{\circ}$, whereas the minimum $(0.861 \mathrm{E}+02 \mathrm{~Pa})$ in the case when the blade angular position is $45^{\circ}$. For four blades design the maximum static pressure drop $(2.547 \mathrm{E}+02 \mathrm{~Pa})$ is found for blade angular position of $45^{\circ}$, whereas the minimum $(1.81 \mathrm{E}+02 \mathrm{~Pa})$ when the blade angular position is $0^{\circ}$. The positive pressure on the frontal surface of the blades in front of air stream, and a negative pressure on the other sides of the back surface for the blades are clearly seen in Fig. 3. Fig. 4 shows the velocity contours for three and four blades rotor at $0^{\circ}$ and $45^{\circ}$ blade angular positions. The velocity in the region of wind turbine rotor is much larger than that in the upstream or air flow. However, the velocity of wake away from the rotor is smaller than the velocity of upstream air flow. This phenomenon is mainly caused by the existence of gradient between the wake velocity and the velocity of downstream free air flow.

\section{Conclusions}

The three dimensional numerical investigation is carried out to predict the aerodynamics of the three and four blades vane type vertical axis wind turbine having movable vanes using CFD software GAMBIT and ANSYS FLUENT where shear Stress Transport (SST) k- $\omega$ turbulence model is used. The flow field was simulated numerically at fixed vanes position and fixed wind velocities. The predicted results show that: (1) the drag coefficient increases with the increase in turbine frontal area and decreases with the decrease in its frontal area, (2) Cd for four blades design is higher than three blades design indicating that the four blades design is more efficient from three blades design, (3) the maximum static pressure drop for four blades design $(2.547 \mathrm{E}+02 \mathrm{~Pa})$ is found for blade angular position of $45^{\circ}$ and minimum $(1.81 \mathrm{E}+02$ $\mathrm{Pa}$ ) when the blade angular position is $0^{\circ}$ both values being greater than those obtained for three blades design, (4) the velocity in the region of wind turbine's rotation was much larger than that of the upstream air flow. There is a wake dispersion region in the downstream of the wind turbine. The results are found to be similar in nature to those reported for VAWT having different blade designs.

\section{References}

[1] Wanga H, Wanga J, Yaoa J, Yuanb W, Caoa L. Analysis on the aerodynamic performance of vertical axis wind turbine subjected to the change of wind velocity. In: Proc. of Advances in Computational Modeling and Simulation, J Procedia Engineering, 2012:213-219.

[2] Rolland S, Newton W, Williams A, Croft T, Gethin D, Cross M. Simulations technique for the design of vertical axis wind turbine device with experimental validation. Journal of Applied Energy, 2013; (111):1195-1203.

[3] Aranake AC, Lakshminarayan V, Duraisamy K. Computational analysis of shrouded wind turbine configurations. In: Proc. of 51st AIAA Aerospace Sciences Meeting including the New Horizons Forum and Aerospace Exposition, Grapevine, 2013: 1-17.

[4] Kacprzak K, Liskiewicz G, Sobczak K. Numerical investigation of conventional and modified savonius wind turbines. Journal of Renewable Energy, 2013; (60):578-585.

[5] Mohamed M, Janiga G, Pap E, Thevenin D. Optimal blade shape of a modified savonius turbine using an obstacle shielding the returning blade. Journal of Energy Conversion and Management, 2011:230-242.

[6] Nathan EF, David M, Allison L, Jesse F. Design and analysis of the aerodynamic components for low altitude implementation in remote rural villages. In: Proc. of 5th Energy Sustainability, 2011:7-10. 